\title{
Making participation accessible for vulnerable clients
}

\author{
Lou laquinto \\ RMIT University
}

\begin{abstract}
Despite forty years of research, community sector service providers still find operationalising participation in their practice confusing and difficult. This paper presents the results of a preliminary study that begins to question why this is so and what can be done about it? The study examines the meaning and importance of participation determined by a review of the academic literature, by soliciting feedback from a range of stakeholders in community sector organisations, including service users with complex barriers to participation, staff, and board members. The participants' perspectives, views and experience of participation were obtained through the use of semi-structured interviews. The data generated a number of telling examples of the impact organisational culture has on service delivery and how the values of the leadership shape the organization, as well as illustrations of the principles that underpin participation expressed from the standpoints of the three participant groups. Study findings underscore the critical importance for service providers to consider their culture and its influences.
\end{abstract}

Keywords: organisational culture, vulnerable clients, client participation

The appearance of Arnstein's Ladder (1969) and her use of the term "citizen participation" marked the beginning of study and research into participation as a means to an end. Many authors have acknowledged the significance of Arnstein's work as the first attempt at presenting a definitive model of participation (Hart, 1992; Florin, 2004; Wong, Zimmerman \& Parker, 2010) but an equal number have criticized it for being hierarchical and adversarial in nature (Treseder, 1997; Lardner, 2001; Tritter \& McCallum, 2006). At present, community sector service providers find little understanding in the academic literature that facilitates an emphasis on participation in their practice. A summary of the popular models of participation presented in Table 1 offers some insight into the complexity faced in effectively implementing client participation. As this table suggests, service providers' difficulty begins with the realization that an off-the-shelf model of participation that meets the needs of their cohort of clients - the skills of their staff - the nature of their community's aspirations for their service delivery - does not exist.

This paper seeks to offer community sector service providers clarity of what is required to imbed client participation in their service delivery. I begin with an exploration of how Arnstein's (1969) model frames client participation and why her model fails human services clients and service providers. This is followed by a description of the key influences for change in the delivery of human services - a shift from what is sometimes characterized as a positivist perspective, which sought to objectively determine the best strategies for service delivery through the systematic application of technocratic principles, to an alternative, more collaborative, conception of service provision based on the human right of a person to participate in the decisions that affect their life. In the final section I present the results of my study and describe how the insights from the academic literature were applied to this original

Corresponding Author: Lou laquinto (lou.iaquinto@rmit.edu.au) 
research that sought the experiences of participation from service users, staff and board members at three community sector services in Victoria.

Table 1: Six Models of Participation

\begin{tabular}{|c|c|c|c|c|c|}
\hline $\begin{array}{l}\text { Arnstein, } \\
\text { Ladder of } \\
\text { Citizen } \\
\text { Participation } \\
\text { (1969) }\end{array}$ & $\begin{array}{c}\text { Hart } \\
\text { Ladder of } \\
\text { Children's } \\
\text { Participation } \\
\text { (1992) }\end{array}$ & $\begin{array}{c}\text { Treseder, } \\
\text { Degrees of } \\
\text { Participation } \\
\text { (1997) }\end{array}$ & $\begin{array}{c}\text { Checkoway, } \\
\text { Five types of } \\
\text { Participation } \\
\text { (1998) }\end{array}$ & $\begin{array}{c}\text { Lardner, } \\
\text { A Model of } \\
\text { Participation } \\
\text { (2001) }\end{array}$ & $\begin{array}{c}\text { Sheir, } \\
\text { Model of } \\
\text { Participation } \\
(2001)\end{array}$ \\
\hline $\begin{array}{l}\text { Early model of } \\
\text { participation } \\
\text { on which } \\
\text { many others } \\
\text { are based. } \\
\text { Concerned } \\
\text { with achieving } \\
\text { power and } \\
\text { control for } \\
\text { citizens. }\end{array}$ & $\begin{array}{l}\text { Adapts } \\
\text { Arnstein's } \\
\text { model and } \\
\text { provides } \\
\text { useful } \\
\text { examples of } \\
\text { false } \\
\text { participation. }\end{array}$ & $\begin{array}{l}\text { Rejected } \\
\text { ladder model } \\
\text { and placed } \\
\text { degrees of } \\
\text { participation } \\
\text { in a circle. } \\
\text { Each degree } \\
\text { a suitable } \\
\text { form of } \\
\text { participation. }\end{array}$ & $\begin{array}{l}\text { Concerned } \\
\text { more with } \\
\text { integrating } \\
\text { participation in } \\
\text { youth } \\
\text { programs and } \\
\text { emphasised } \\
\text { viewing young } \\
\text { people as a } \\
\text { resource } \\
\text { rather than a } \\
\text { problem. }\end{array}$ & $\begin{array}{l}\text { Presents } \\
\text { model as a } \\
\text { guide to } \\
\text { comparing } \\
\text { and } \\
\text { assessing } \\
\text { methods of } \\
\text { participation } \\
\text { to determine } \\
\text { who holds } \\
\text { the power. }\end{array}$ & $\begin{array}{l}\text { Concerned } \\
\text { with } \\
\text { individual } \\
\text { and } \\
\text { organisationa } \\
\text { I level of } \\
\text { commitment } \\
\text { to } \\
\text { empowering } \\
\text { children. }\end{array}$ \\
\hline $\begin{array}{l}\text { Arnstein } \\
\text { sought to } \\
\text { change the } \\
\text { social order of } \\
\text { communities } \\
\text { by giving } \\
\text { people the } \\
\text { power to } \\
\text { make } \\
\text { decisions and } \\
\text { develop and } \\
\text { control } \\
\text { processes for } \\
\text { improvement. }\end{array}$ & $\begin{array}{l}\text { Hart's } \\
\text { purpose was } \\
\text { to ensure } \\
\text { children were } \\
\text { given an } \\
\text { opportunity to } \\
\text { participate at } \\
\text { the level they } \\
\text { choose. }\end{array}$ & $\begin{array}{l}\text { Treseder } \\
\text { was focused } \\
\text { more on the } \\
\text { systems and } \\
\text { processes } \\
\text { that } \\
\text { supported } \\
\text { and } \\
\text { empowered } \\
\text { children to } \\
\text { participate. }\end{array}$ & $\begin{array}{l}\text { Checkoway } \\
\text { sought to find } \\
\text { the value and } \\
\text { skills within } \\
\text { each } \\
\text { individual } \\
\text { youth and to } \\
\text { assist them to } \\
\text { use their skills } \\
\text { to improve } \\
\text { their } \\
\text { neighborhood } \\
\text { s. }\end{array}$ & $\begin{array}{l}\text { Lardner's } \\
\text { priority was } \\
\text { to empower } \\
\text { young people } \\
\text { to participate } \\
\text { at whichever } \\
\text { level they } \\
\text { wish. }\end{array}$ & $\begin{array}{l}\text { Shier's } \\
\text { model } \\
\text { combines the } \\
\text { work of } \\
\text { Lardner and } \\
\text { Hart by } \\
\text { empowering } \\
\text { both children } \\
\text { and } \\
\text { practitioners } \\
\text { to create a } \\
\text { model that } \\
\text { requires } \\
\text { commitment } \\
\text { from } \\
\text { practitioners. }\end{array}$ \\
\hline
\end{tabular}

\section{Background}

Arnstein's (1969) seminal work "A Ladder of Citizen Participation" has inspired a wide range of applications, contestations, extensions, and further developments of the concept, which Arnstein characterised as the "heated controversy over citizen participation, citizen control and maximum feasible involvement of the poor" (p. 216). When the article was written, Arnstein was involved in urban renewal programs in several of America's largest cities. She was principally concerned with the apparent powerlessness of the people in these communities, who, in spite of the rhetoric and euphemisms regarding citizen participation, were severely diminished by their poverty and experience of racial discrimination to freely participate in decision-making. She presents accounts of bias in approving funding applications through numerous illustrations of community groups being manipulated, placated and victimised by those in control (powerholders). These accounts, she suggests, reflect the racist and paternalistic behaviour of a group of professionals, which mark sharing their power as unthinkable. In Arnstein's experience, the philosophy of involving service users in decisions that affect their lives had yet to emerge. 
Bacchi's (2009) application of Foucault to the analysis of problem representations appears to be relevant for reflecting on Arnstein's (1969, pp. 219-222) illustrations of the disrespectful behaviour of the powerholders and grasping the representation of participation in her model. Bacchi (2009, p. 16) notes Foucault's (1982, p. 208) use of the term "dividing practices," a dynamic that divides people in terms of the 'haves' versus the 'have-not' citizens, to use Arnstein's terms. Arnstein's accounts are explicit examples of what Bacchi (p. 17) describes as the "lived effects" of dividing practices. The impoverished neighbourhoods - the subjects of the federal programs Arnstein explains - are where minority groups live. The dividing practices of the white male powerholders is partly their assumption the minority groups must be the problem and the reason why their neighbourhoods need renewal. This definition of the problem results in their resolve that a professional in authority must decide what needs to be done rather than neighbourhood residents being able to decide for themselves. The reality of a lifetime of racial prejudice, poverty, lack of employment and educational opportunities these citizens have experienced is "closed off" by the powerholders (Bacchi, 2009, p.16). For Arnstein, confronted by examples of professionals, some who may have been well intentioned but suffering from institutionalized thinking, the problem is the powerlessness of the residents. Her solution is the transfer of power to the have-nots. This imagines Arnstein's model - in the human services context - as pitting clients against service providers in an overt struggle for power and control (Tritter \& McCallum, 2006, p. 157). This presents potential problems for clients, service providers and their communities.

Arnstein's piece was also published at a time when, professionalism was the dominant approach in human services. People receiving these services had little opportunity to make decisions and exercise control over their lives (Tarulli \& Sales, 2009, p. 104). Taking place concurrently with the publication of Arnstein's Ladder were a number of social movements that began to advance the discussion on participation and the human right of service users to have control of decisions that affect their lives. These social movements included the Civil Rights movement, which greatly influenced the disability rights, and children's rights movements (Chesters \& Welsh, 2011, p. 63). The effect of the activism of these movements was not only to enhance the diversity of the literature on participation; it also signaled the shift away from the era of professionalism that reflected the positivist belief that science and engineering principles would solve the social and technical problems of the world. Schön $(1983$, p. 39) refers to this as "technical rationality," which conceives professional practice as primarily problem solving where problems are solved by selecting the best solution available. Schön's (p. 151) response is that, when faced with unique, complex problems that initially make no sense, the practitioner must engage in a "reflective conversation with the situation" that explores the possible decisions to be made as well as the ends and means of the decision. For service providers, imbedding client participation in their practice is a problem that exists in what Schön (p. 42) refers to as the "swampy lowland" of confusing situations where problems are of greatest concern to the persons affected.

Drawing on this theoretical background, I would argue that the first and, in my view, the most important step for service providers is reflecting on the dividing practices of professionals. Human services often declare the values that underpin their approach to practice through mission and value statements. Respect is a value often included in such statements and, for some organisations, living their stated values seems effortless. Their values are observable in their interactions with staff and clients and they appear to see value in every person that walks in their door. Given the examples of poor quality services and, occasionally, systemic abuse that appear in the media, it could be argued that, for other organisations, respect for clients and frequently staff, is more of an aspiration than a reality. Sennett $(2003$, p. 3) equates the lack of respect for an individual as rendering them invisible. Strikingly, some professionals continue to exhibit an inability to see value in taking the time to gain an understanding of the experience of being a service user. Gupta (2015, p. 134) speaks to the resulting experience of shame by service users and how such attitudes and practices can make the simple fact of using a service humiliating. The literature offers examples of 
professionals resisting client participation for fear of losing power and control, perceiving participation as an attack on their professional expertise (Bennetts, Cross \& Bloomer, 2011, p. 160). Heffernan (2008, p. 382) suggests that service providers have adopted the language of service user involvement in line with government policy but have not changed their behaviour - continuing to treat the concept of service user involvement as rhetoric, rather than as a structuring and central element of professional practice. Gupta and Blewett (2008, p. 466) describe the feelings of oppression and discrimination families experience because of their poverty and status as a service user and report preconceived ideas of professionals - such as that a person must be a bad parent because they are part of the family services system. The values and attitudes of professionals determine how an organisation conducts its business and how it treats its clients and staff. Prejudices, such as those revealed in Arnstein's accounts, increase exclusion from participation and contribute to a person's vulnerability.

What this discussion highlights is the significance of the personal values of professionals, particularly in human services, as the essential pre-condition for the practice of client participation - a factor well known to service providers but omitted from Arnstein's ladder. Although my purpose is not to redesign her ladder, I argue that, if we consider a rung for Values, this begins to alter the perspective of each rung - shifting the ladder from one reflecting rising degrees of citizen power and control, to one that denotes the pre-conditions necessary for service providers to implement a process of client participation which takes account of: client needs; their understanding of participation and desire to participate; and the leadership that drives a professional culture that demonstrates a commitment to involving clients in every aspect of their service delivery. All of which are examples of good practice in human services (Ife, 1997, p. 56). As Heffernan (2009, p. 382) notes, client involvement needs to start at the first contact between client and service provider.

The previous discussion, while not an exhaustive review of the academic literature or models of participation, presents Arnstein's (1969) ladder as a typology that began to formalize the ideals of client participation. My goal in the study to follow is to highlight the question of how service providers are meant to operationalise these ideals. What follows represents an exploratory examination of the organisational processes of participating community sector organisations that contribute to or detract from establishing relationships between workers and clients. This study was designed as a preliminary test of whether a range of stakeholders - including service users with varying needs, staff and board members at a range of social service organisations - would find the models drawn from the academic literature on participation, useful, meaningful, and valid as a means to help them articulate their own experience and approach to client participation.

\section{Method}

A collaborative framework utilising semi-structured interviews was the method chosen for this study. In adopting an "advocacy/participatory approach," the research was undertaken with participants as active collaborators. This perspective concerns itself with changing real practice and offers participants opportunities to understand and examine their own knowledge, values and interactions (Creswell, 2007, p. 21). In his discussion on effective thematic analysis Boyatzis (1998, pp. 12-16) lists three major obstacles all of which point to the researcher's "projection, sampling and, mood and style." Nevertheless, Creswell (2007) reminds us that qualitative research follows the established building blocks of all research and was therefore considered to be appropriate for the purpose of the current study

Ethical approval for this research was obtained from the RMIT University College Human Ethics Advisory Network of the Science, Engineering and Health College, who approved this study in accordance with the "National Statement on Ethical Conduct in Human Research". 
A critical aspect of this research was obtaining informed consent from participants with cognitive impairments. Arscott, Dagnan and Kroese $(1998,1999)$ adapted an Ability to Consent to Treatment Questionnaire developed by Morris, Neiderbuhl, \& Mahr (1993) to determine the ability of people with cognitive impairments to consent. This process was therefore applied to this research.

Semi structured interviews were held with twenty-nine participants from three community sector organizations in Victoria. A purposive sampling method (Yin, 2011; Creswell, 2007; Polit \& Beck, 2006) was applied to the recruitment of these organizations, which provided participants from three categories including clients, staff and board members. The participants from these organizations were chosen because they could "purposefully inform an understanding of the problem" (Creswell, p. 125) and therefore provide data that was unavailable elsewhere. Sixteen clients, including seven men and nine women between the ages of 18 and 74, participated in the study. Ten of these participants included those with sensory and/or cognitive impairments, one client was a parent of a service user and the remaining client participants received services from a provider of youth and family programs. Seven staff consisting of two men and five women, all at manager or team leader level participated. The remaining six participants consisting of three women and three men who were board of management members at the participating community sector organisations. The three organisations varied in size from, less than 100 clients to over 1000 clients. The services provided a range of human services to young people, families, adults and children some with impairments - that included emergency accommodation, case management, day activity programs, long term and respite accommodation.

All interviews were digitally recorded, transferred into NVivo 10 (2012) and transcribed as soon as possible after the interview. I employed Yin's (2011, pp. 178-183) "five phases of analysis" in my approach, which begins with ordering the data (Compiling). Recordings and transcripts were listened to and read repeatedly and coded for factors that contribute to forming and maintaining relationships between: clients; clients and staff; clients and board members; between staff; and staff and board members. My initial analysis of the data generated five themes but, as the analysis (Disassembling/Reassembling/Interpreting) progressed, this was reduced to a final list of three themes (Concluding) as presented in Table 2.

Table 2: Themes and Descriptors

\begin{tabular}{ll}
\hline Themes & \multicolumn{1}{c}{ Descriptor } \\
\hline Values \& Beliefs & $\begin{array}{l}\text { Personal and organizational values influence an individual's } \\
\text { approach to their work and form the culture of how an entity } \\
\text { conducts its business. }\end{array}$ \\
Collaboration & $\begin{array}{l}\text { The principles of equity, fairness and the acknowledgement of } \\
\text { the importance of the quality of client/staff relationships in } \\
\text { achieving client goals. }\end{array}$
\end{tabular}

Choice \& Decision Opportunity to influence the available choices and exercise the Making right to make decisions without being controlled by others.

\section{Results}

A sample of the data obtained is presented to provide a picture of the participants in the study and to illustrate the meaningfulness of the data. Pseudonyms are used. These snapshots are presented from the perspective of clients, staff and board member participants. 


\section{Client participant $A$}

Natalie is in her early twenties, has two young children and a partner. She utilises family services and at the time of her interview had been a client of the CSO for eighteen months. Natalie was referred to the CSO by her local hospital after being admitted for self-harming injuries. Natalie doesn't drive and has the occasional anxiety attack.

At the interview Natalie described the differences between her first caseworker and the one she has now had for six months. Both caseworkers were from the same CSO. Here is a sample of the discussion:

My new caseworker will sit down with us (partner) and talk one to one, not with just one of us. My other caseworker it didn't seem to matter whether I was in and out of the room. My new caseworker helps more in the sense of getting things done; it's not all up to me. For example, if I was to say to [new caseworker] I need to get in touch with my child's doctor, she would say, 'here's the phone ring them now', [previous caseworker] would say, 'you need to get that done.' Things like that help a lot more. I don't want to sound selfish but with my illness [anxiety] I really need to be pushed, I can't be expected to say here, go and do this. I need to have someone there to say, 'I can take you to your appointment and be with you and help you write things down' because I am really bad at things like that.

Natalie provides a description of what, for her, is the right 'help' she needed to 'get things done'. Her original caseworker was well meaning in attempting to have Natalie take responsibility and do things for herself. This approach is appropriate for some, but not for Natalie. Natalie understands she is a responsible parent but is concerned she will get anxious and forget. As a result she gets stressed, misses appointments, and forgets to write things down. The new caseworker is more respectful of Natalie as a person and does simple things like ensuring her partner is included in the conversation, which takes place at home, not the office.

Natalie's responses also demonstrate the importance of the quality of the relationship the individual worker establishes with a client. The new caseworker has understood that a more collaborative approach was required and illustrates the caseworker's knowledge of the value of treating clients with respect and seeing them as individuals. Like the previous caseworker, the new one understands Natalie's need to take responsibility for getting things done but applies a method more appropriate for Natalie.

\section{Client participant $B$}

Fiona is in her fifties, has hearing and vision impairments which made it necessary for an interpreter to be present during the interview, is now receiving case management and community access services from her CSO and has been a client of this service provider for more than twenty years. Fiona lives in her own apartment and receives an individual support package (ISP) that she's had for about ten years. She also receives some additional help from the local council. Fiona feels she has no control over how her support package is spent:

I feel out of control of what's going on with the ISP. I say l'd like to do this and they [CSO] say, 'that can't happen.' I can't get the support on that day. There are always lots of 'cants'. They are very much in control of how the ISP works for me. I think last year they started this new thing where I can control some of the money and that's a really good start. I suppose it's going to take a little while before I am in control of more of the money. 
When I asked her how she got on with the staff she responded by saying: "do you want both the positives and negatives? Fiona went on to say that she enjoyed the services at [CSO] but:

Sometimes things go wrong. The board makes decisions that we [clients with similar impairments] don't think are right for us. I think recently they've changed some of the policies and have become quite strict and firm about things. The rules have gotten a lot tighter so sometimes it makes it more difficult to get exactly what you want all the time, so that's happening in more recent times I suppose.

Fiona's comments highlight the difficulty clients and organisations have in determining how individual support packages (ISP) are monitored and controlled and the difference in perspectives as to what is required. At present, these funds are allocated to a person to assist them to meet their support needs. CSOs are faced with the problem of balancing their financial accountability with client need and choice. Nevertheless, Fiona has been a client of this CSO for two decades and has been receiving an ISP for half that time. In spite of this, the CSO has failed to recognise Fiona's capacity to independently manage her finances.

A second concern is Fiona's mention of the CSO's process regarding policy changes which, on the face of it ignores the views and needs of clients and seems more concerned with increasing control and reducing flexibility and choice for clients.

\section{Staff participant $A$}

Mike is in his fifties and is the team leader of a non-residential service for people with intellectual disabilities and complex communication needs. He has been at the CSO for more than five years and has previously worked in residential services for people with disabilities. When I asked him how he would describe his role in the CSO he responded in this way:

I think it's a fairly important role I do here. I take it seriously. I think the client base I work with are the most marginalised people in our society. They haven't got a voice. I really take that seriously in how and what we can give them. Of course most of them have complex communication needs, we have to take the time to make an effort to respond and work with them. A lot of the time we might just achieve little things; some people might walk away at the end of the day but if we can make a slight difference; I sum it up at the end of the day, what did we do here today? Well, such and such had a good day. I think we take it step-by-step, day-by-day as to what we can give them; a bit of quality. I think it is the most important thing with my job is what I can do for these guys.

Mike's comments reflect his personal and professional values. He cares about what he does, understands the importance of his role and purpose in the lives of clients. Through his experience of working with this group of clients he has learned that everyone has a way of communicating. People need to take the time to get to know the person and become familiar with how they communicate in order to give them opportunities to make choices.

The findings from Mike's interview relate to all three themes and demonstrate his approach to engage clients with complex communication needs. Mike achieves this through his personal and professional beliefs, working hard to establish a collaborative relationship by learning how the client communicates and ensuring his staff appreciate the significance of working in this way.

\section{Staff participant $B$}

Colleen is a manager in a family services CSO, she is in her forties and has been at the CSO for three years. I asked Colleen what sort of information she receives to judge the quality of her work. She described the following process: 
The clearest one is, at the end of every family intervention I do a telephone survey with the client. I explain the conversation is a focus on how we provide the service. Not so much about the individual worker. I have a range of questions. I ask them what best suits their experience. I make three attempts to contact the family. I don't want to be abusive. We don't send out questionnaires because past experience is they don't get read or sent back. Sometimes we arrange for some of the families to come in because it may be easier to do it face to face. Another client was deaf so she needed an interpreter. We try to best support the client to provide the information. That's our main source of formal feedback. But throughout the life of all of the team's interventions because it's about relationships and the encouragement for staff to be checking in along the way, and if there seems to be a blockage for example around relationships if they're not getting somewhere to be having those conversations with the family. The relationship is fundamental to being able to get anywhere with the intervention you want to put in place.

When Colleen was asked what the personal values were that she brought to her work she said in part:

To be working with people is to continue to have a sense of hope, if you don't have it you shouldn't be doing this work. A sense of curiosity just stands out for me. Unless you have a sense of curiosity about a person and a person's situation you often aren't going to understand what is going on.

In her responses Colleen provides three significant examples of what is required for effective service user participation. Colleen's first example is her approach to obtaining feedback from clients regarding the service they received. In describing her process, Colleen highlights the sensitive approach she uses in contacting clients and how she ensures clients are supported to respond to her questions. Her second example is her practice of focusing on the quality of the relationship between the client and the caseworker. Critical to this is her emphasis on regularly checking back with staff to see if the relationship is working and providing guidance and support if necessary. Colleen's final example is her personal values, which were reflected in her comments about having a "sense of hope" and a "curiosity" about clients and their situation. For Colleen, her values underpin the approach she takes which focuses on the quality of the relationship between client and staff, which she believes, is critical to achieving successful outcomes for clients and seeks feedback from clients once they complete the program. The data from her interview related to all three themes.

\section{Board member participant $A$}

Mary is in her thirties and has been a board member for five years; is currently employed in the real estate industry, and has a limited background in human services. When asked if she thought there was a good match between her personal values and the values of the CSO Mary responded in this way:

Having gone through the exercise of putting together our mission and our values which some people see as just one of those corporate things but the pride everybody took coming to our mission really was just a clarification that staff and board members, everybody, have that same set of values, it's really interesting putting the clients first.

This participant's reflection is representative of two of the three CSOs in the study. Both staff and board member participants in these organisations emphasised the importance of having shared values across the organisation. This data supports my view that participation for service users begins with personal values that underpin the appropriate organisational 
values that are shared by all. In practice, this contributes to a purposeful environment for staff and a supportive but challenging environment for service users.

\section{Discussion}

Participants' responses would appear to represent illustrations of what was important to them as individuals, rather than representations of themselves as a client, staff or board member. However, what was important for clients was how they were treated and in summary, they expect to be treated fairly and with respect. It is clear they appreciate flexibility in service delivery; assume their privacy will be respected and want services that meet their specific needs. What clients valued was the knowledge that there was at least one person in the organisation they knew would help them if they asked.

Personal values were articulated by staff and board member participants as a set of beliefs that underpin how they approach their work and in particular their process of developing relationships with clients. Having shared values seemed to strengthen the resolve of all staff to work together for a common purpose, which in the case of the CSOs in this study, was to put the needs of clients first.

Shim (2010) has defined organisational culture as the way things are done in an organisation. In the case of one CSO in the study, there was a mismatch between the articulated values of the board of management participants and the staff participants. The data from board members implied they valued and respected the rights of clients when the data from staff suggested the board members valued protection and control of clients rather than valuing them as individuals. In the case of this CSO the data from staff interviews presented of picture of board members as being a burden to their practice with clients. This was in contrast with the two other CSOs where the interview data reflected a sense of excitement and satisfaction with the idea that board members and staff shared similar values.

There is a strong inference from the data that how a staff member treats a client stems from the staff members' personal values in the first instance, which underpins organisational values that have a positive impact on service delivery. An organisational culture that includes the appropriate shared values is the foundation for meaningful client participation in practice. What came through from the interview data from all participants was the significance of the quality of the relationships between staff, staff and clients and staff and management. From a client point of view, there was no interest or necessity to pursue a relationship with board members or senior staff. Their relationship with individual staff was the only one that mattered.

The results indicate a lack of real choice in regards to the programs and services available. None of the client participants were able to describe any choices or decisions they made in regard to the services they received. Some differences occurred in a CSOs' approach to service delivery, which was often the result of the initiative taken by individual staff. This may be a reflection of an individual's competence as well as their attitudes and beliefs. One CSO in the study seemed to take an inflexible approach where the others were more inclined toward flexibility and working collaboratively with the client.

A significant issue for some participants was their limited capacity to make choices. The interview data included descriptions of how staff support clients by making decisions in their interest but it is the right of each individual to make choices regardless of their capacity to choose. To this end, there appeared to be little opportunity to exercise choice of any description whether a client was capable of making a choice or not. For most clients, the only choices were to accept the service offered and decide daily whether they attended the service. 
The data provided clear examples of three important factors that contribute to client participation through the development of collaborative relationships between client and service provider. This first is trust, which applies to all participants and is inclusive of any positive relationship. This is supported by the work of Webb (2008) and others (Beadle, Needham \& Dearing, 2012; Gupta \& Blewett, 2008) who list trust as a necessary factor for satisfaction with a relationship that facilitates participation. The second is the need to concentrate on providing opportunities to give feedback and discuss their needs and experiences which is in turn dependent upon the third factor: the need for service providers to manage their professional culture and challenge assumptions about the balance of power between professionals and clients (Campbell, 2009,). Service providers can address this if professionals reflect on their preconceived notions of clients and learn to appreciate the value of the experiences of clients, which is accomplished by asking questions and listening to what clients have to say (Webb, 2008).

In conducting this research, I found service providers to be enthusiastic about wanting to improve their practice of participation, which they believed necessary for both their clients and service delivery. One CSO had the additional need to clearly define their participative processes in order to comply with the requirements of the National Disability Insurance Scheme (NDIS). All were unclear on how to do it. Nevertheless, participants reinforced my belief that service providers are able to recognize and construct good practice in their service delivery. Their hesitation in operationalising what they consider a process for client participation appears to be their perception that participation is something that needs to be added onto - not an existing component of - good practice.

A second feature of this research was the striking examples of organisational culture expressed by all three participant groups. For purposes of this paper it was necessary to omit detailing the extent of these examples but they require service providers to remain vigilant of three features of their organisation's culture: examples of professional and personal attitudes towards clients, particularly those that mirror Schön's (1983) views of "professional" practice; the quality of the collaborations between all actors; and attitudes toward and capacity to manage risk which may require services to consider Bacchi's (2009) framework for analysing problem representations.

My final conclusion relates to why a mature intelligent woman with sensory impairment - who has been a client of the same organisation for many years - was not allowed significant control over her support package? In analyzing this and comments from other participants I came to believe this particular service provider was more concerned with maintaining power and control of both resources and clients. This may reflect Arnstein's (1969) experience of the attitudes of professionals that, 47 years later, present as a significant barrier to the full participation of clients.

My stated intention was to provide service providers with clarity in how they might begin to operationalise client participation in their practice. Based on the data obtained, I am satisfied that client participation is an aspect of good practice but what requires further examination are first; the aspects of service delivery that enable client participation and second; what are the barriers to client participation? In addition, what is also required is a practical method for organisations to begin a professional conversation on what client participation means for their particular cohort of clients. To this end, it would appear that individual and organizational values need to be explicitly considered. 


\section{References}

Arnstein, S. R. (1969). Eight rungs on the ladder of citizen participation. Journal of the American Institute of Planners, 35(4), 216-224.

Bacchi, C. (2009). Analysing Policy: What's the problem represented to be? Frenchs Forest: Pearson.

Barnes, D., Carpenter, J., \& Bailey, D. (2000). Partnerships with service users in interprofessional education for community mental health: a case study. Journal of Interprofessional Care, 14(2), 189-200.

Beadle, M., Needham, Y., \& Dearing, M. (2012). Collaboration with service users to develop reusable learning objects: The root to success. Nurse Education in Practice, 12(6), 352-355.

Beresford, P., \& Croft, S. (2004). Service Users and Practitioners Reunited: The Key Component for Social Work Reform. British Journal of Social Work, 34(1), 53-53.

Bennetts, W., Cross, W., \& Bloomer, M. (2011). Understanding consumer participation in mental health: Issues of power and change. International Journal of Mental Health Nursing, 20(3), 155-164.

Bloor, G., \& Dawson, P. (1994). Understanding professional culture in organizational context. Organisational Studies, 15(2), 275295.

Boyatzis, R. E. (1998). Transforming Qualitative Information. Thousand Oaks: Sage.

Brownlea, A. (1987). Participation: Myths, realities and prognosis. Social Science \& Medicine, 25(6), 605-614.

Burnes, B., \& Pope, R. (2007). Negative behaviours in the workplace: A study of two primary care trusts in the NHS. International Journal of Public Sector Management, 20(4), 285-303.

Campbell, M., \& Martin, M. (2009). Reducing health inequalities in Scotland: the involvement of people with learning disabilities as national health service reviewers. British Journal of Learning Disabilities, 38(1), 49-58. Doi:10.1111/j.1468-3156.2009.00562.x

Cavet, J., \& Sloper, P. (2004). Participation of disabled children in individual decisions about their lives and in public decisions about service development. Children \& Society, 18(4), 278-290.

Checkoway, B. (1998). Involving young people in neighbourhood development. Children and Youth Services Review, 20(9-10), 765-795.

Concannon, L. (2005). Planning for life: Involving adults with learning disabilities in service planning. London: Routledge.

Cornwall, A. (2008). Unpacking 'Participation': models, meanings and practices. Community Development Journal, 43(3), 14.

Creswell, J. W. (2007). Qualitative Inquiry \& Research Design: Choosing Among Five Approaches. Thousand Oaks: Sage.

Florin, D. (2004). Public Involvement in Health Care. British Medical Journal, 328 (7432).

Gupta, A., \& Blewett, J. (2008). Involving services users in social work training on the reality of family poverty: A case study of a collaborative project. Social Work Education, 27(5), 459-473.

Hart, R. (1992). Children's Participation: The Theory and Practice of Involving Young Citizens in Community Development and Environmental Care. London: Earthscan Publications.

Harris, J. (2003). Time to make up your mind: Why choosing is difficult. British Journal of Learning Disabilities, 31(1), 3-8.

Hickey, G., \& Kipping, C. (1998). Exploring the concept of user involvement in mental health through a participation continuum. Journal of Clinical Nursing, 7(January), 83-88.

Ife, J. (1997). Rethinking Social Work: Towards critical practice. Melbourne: Longman.

Lardner, C. (2001). Exploring Good Practice in Youth Participation: A Critical Review. Edinburgh: Clarity. 
Padilla, M., Angel, Sahagu'n, Cabero, N. r., Marzo, Parerjo, S. P. S., \& Gonza'lez, M., Martinez. (2007, July). Approaches to participation: some neglected issues. Paper presented at the Fifth Critical Management Studies Conference, Manchester, UK.

Schön, D. A. (1983). The Reflective Practitioner: How professionals think in action. London: Maurice Temple Smith Ltd.

Shier, H. (2001). Pathways to participation: openings, opportunities and obligations. Children \& Society, 15(2), 107-117.

Shier, M. L., Jones, M. E., \& Graham, J. R. (2011). Sociocultural Factors to Consider When Addressing the Vulnerability of Social Service Users: Insights from Women

Experiencing Homelessness. Affilia, 26(4), 367-381.

Shim, M. (2010). Factors influencing child welfare employee's turnover: Focusing on organizational culture and climate. Children and Youth Services Review, 32(6), 847856.

Spence Laschinger, H. K., Leiter, M., Day, A., \& Gilin, D. (2009). Workplace empowerment, incivility, and burnout: impact on staff nurse recruitment and retention outcomes. Journal of Nursing Management, 17(3), 302-311.

Tarulli, D., \& Sales, C. (2010). Self-determination and the emerging role of personcentered planning. In F. Owen \& D. Griffiths (Eds.), Challenges to the Human Rights of People with Intellectual Disabilities (pp. 102-123). London: Jessica Kingsley.

Treseder, P. (1997). Empowering children and young people. London: Save The Children.

Tritter, J. Q., \& McCallum, A. (2006). The snakes and ladders of user involvement: Moving beyond Arnstein. Health Policy, 76 (2), 156-168.

Volti, R. (2008). An Introduction to the Sociology of Work and Occupations. Los Angeles: Pine Forge Press.

Webb, S. A. (2008). Modelling service user participation in social care. Journal of Social Work, 8(3), 269-290.

Wong, N. T., Zimmerman, M. A., \& Parker, E. A. (2010). A Typology of Youth Participation and Empowerment for Child and Adolescent Health Promotion. American Journal of Community Psychology, 46(1-2), 100-114. doi: http://dx.doi.org/10.1007/s10464010-9330-0.

World Health Organisation. (1978, September). Primary health care (report of the International Conference on Primary Health Care, Alma Ata, USSR). Paper presented at the International Conference on Primary Health Care, Alma Ata, USSR. 


\section{Biographical notes}

Lou laquinto has taught at RMIT University in both the VET and higher education sectors since 2007, with a focus on disability, human services leadership, and community sector management. Prior to his time at RMIT University, he spent thirty years managing direct services to clients in a broad range of human services in the government sector. My research interests are service user involvement and the practice of service delivery in community sector organizations 